\title{
Role of gravity waves in vertical coupling during sudden stratospheric warmings
}

\author{
Erdal Yiğit ${ }^{*}$ (i) and Alexander S. Medvedev 2,3 (D)
}

\begin{abstract}
Gravity waves are primarily generated in the lower atmosphere, and can reach thermospheric heights in the course of their propagation. This paper reviews the recent progress in understanding the role of gravity waves in vertical coupling during sudden stratospheric warmings. Modeling of gravity wave effects is briefly reviewed, and the recent developments in the field are presented. Then, the impact of these waves on the general circulation of the upper atmosphere is outlined. Finally, the role of gravity waves in vertical coupling between the lower and the upper atmosphere is discussed in the context of sudden stratospheric warmings.
\end{abstract}

Keywords: Gravity wave, Thermosphere, lonosphere, Sudden stratospheric warming, General circulation model, Parameterizations

\section{Introduction}

The lower atmosphere, where meteorological processes take place, is the primary source of internal atmospheric waves: gravity waves (GWs), planetary (Rossby) waves, and solar tides. These waves can propagate upward and influence the dynamics and thermal state of the middle and upper atmosphere [see, e.g., the reviews of Fritts and Alexander (2003), Laštovička (2006), Yiğit and Medve$\operatorname{dev}(2015)]$. Waves transfer their energy and momentum to the mean flow via breaking and dissipative processes, such as radiative damping, eddy viscosity, nonlinear diffusion, molecular diffusion and thermal conduction, and ion drag (Yiğit et al. 2008). Sudden stratospheric warmings (SSWs) are spectacular events that disturb the circulation in the winter hemisphere. They affect not only the stratosphere, but also their influence extends to the mesosphere and thermosphere. In the upper atmosphere, plasma processes, such as Joule and auroral heating, ion friction, are important processes that shape the morphology and dynamics. Thus, interactions between the lower and upper atmosphere should be considered within the framework of the atmosphere-ionosphere system.

\footnotetext{
*Correspondence: eyigit@gmu.edu

1 Department of Physics and Astronomy, George Mason University, 4400 University Drive, Fairfax, VA 22030, USA

Full list of author information is available at the end of the article
}

Such coupled upper atmosphere-ionosphere system is subject to the following internal and external influences:

- Meteorological effects that encompass internal wave impacts and transient processes of lower atmospheric origin,

- Internal processes due to nonlinearity,

- Space weather effects that are associated with the solar and magnetospheric phenomena.

Among the meteorological effects, we distinguish a direct influence of internal GWs on the upper regions of the atmosphere. Although transient events such as SSWs are technically categorized as stratospheric processes, and, thus, take place above the region of weather-dominated phenomena, they are often referred to as meteorological effects in the context of the upper atmosphere research.

The thermosphere-ionosphere system is highly nonlinear. In the real atmosphere, ion and neutral parameters vary simultaneously, and the resulting changes in the heating ought to contain higher order terms, which is indicative of the nonlinear nature of the system (Yiğit and Ridley 2011a). The atmosphere-ionosphere system is subject to the influence of space weather, which can enhance these nonlinear processes and impact the upper atmosphere (Prölss 2011 and references therein). 
In this paper, we report on the recent advances in understanding the meteorological effects in the upper atmosphere, focusing primarily on the links between SSWs, small-scale GWs, and thermosphere-ionosphere dynamics.

\section{Internal gravity waves}

Internal gravity waves are characteristic features of all stably stratified planetary atmospheres. GWs in the upper atmosphere have been studied for more than 50 years since the early work of Hines (1960). Their importance for the general circulation of the middle atmosphere has been greatly appreciated (e.g., Becker 2011; Garcia and Solomon 1985). However, despite the previous theoretical approaches to GW propagation into the thermosphere (Hickey and Cole 1988; Klostermeyer 1972), only since recently, the role of GWs in coupling the lower and upper atmosphere is being increasingly acknowledged (Fritts and Lund 2011; Heale et al. 2014; Hickey et al. 2010, 2011; Miyoshi et al. 2014; Vadas and Liu 2009; Yiğit et al. 2009, 2012a).

Gravity waves are always present in the lower and upper atmosphere; however, their amplitudes and dynamical importance differ with height. Wave energy is proportional to air density, and, therefore, a conservatively propagating harmonic has a larger amplitude in regions with lower density. In the troposphere, GW amplitudes are relatively small; however, their dynamical importance increases with height and can no longer be neglected in the middle and upper atmosphere.

We next discuss basic principles of how GW processes are represented in atmospheric models, reviewing the underlying assumptions and limitations.

\section{Principles of parameterization of gravity wave processes in global atmosphere models}

Spatial scales of GWs are considerably smaller than the planetary radius. Their sources are highly intermittent, and propagation is strongly dispersive. Therefore, the GW field in the thermosphere is highly irregular and transient. Unlike with distinct large-scale planetary waves, it appears as an ever changing "sea of waves" with occasional well-defined and detectable packets. In many applications, such chaotic wave field and its influence on the large-scale flow can be conveniently described in terms of statistical quantities devoid of the phase information. Examples of the most widely used statistical characteristics for the GW field are the variance $\overline{\phi^{\prime 2}}$, vertical flux of horizontal momentum $\overline{\mathbf{u}^{\prime} w^{\prime}}$, sensible heat flux $\overline{w^{\prime} T^{\prime}}$, etc., where $w^{\prime}, T^{\prime}$, and $\phi^{\prime}$ are the deviations of vertical velocity, temperature and of any field variable from the corresponding mean values, respectively.
General circulation models (GCMs) have spatial resolutions usually much coarser than the scales of GWs. Only few GCMs have endeavored to perform simulations with grids small enough in an attempt to resolve at least a part of the GW spectrum (e.g., Miyoshi and Fujiwara 2008; Miyoshi et al. 2014). In most simulation studies, the effects of subgrid-scale GWs have to be parameterized. This practice means that

1. The average effects must be presented in terms of statistical quantities similar to the described above, and the quantities have to be functions of the background flow. In other words, the parameterization has to self-consistently capture responses of the wave field to the evolution of the resolved large-scale flow.

2. Parameterizations should preferably be based on first principles, that is, they should rely on rigorous laws of physics rather than on a set of empirically introduced (tuning) parameters. Obviously, no parameterization can be devoid of such parameters as they are a substitute for an unknown. But the lesser the number of tunable parameters, the more sophisticated the parameterization is.

3. Parameterizations must be verifiable. This condition means that they have to provide quantities, which can be compared with observations. For instance, GW-induced heating/cooling rates are hard to measure, but temperature variances $\overline{T^{\prime 2}}$ can be.

\section{Assumptions and limitations in gravity wave parameterizations}

In modeling, it is assumed that the majority of GWs are generated in the lower atmosphere. Amplitudes of those excited in the upper layers and propagating downward decrease exponentially with height together with their influence on the mean flow. Therefore, (1) only harmonics propagating upward are considered in parameterizations. This assumption allows one to omit a detailed consideration of the wave reflection, and to (2) apply the Wentzel-Kramers-Brillouin (WKB) approximation. Under the WKB method, (3) only those harmonics are considered whose vertical wavelengths are much shorter than vertical variations of the background fields. Mathematically, the latter can be expressed as $k_{\mathrm{z}} H \gg 1$, where $k_{\mathrm{z}}$ is the vertical wavenumber and $H$ is the density scale height. This limitation becomes very restrictive in the thermosphere, because fast (and long vertical wavelength) harmonics have more chances to penetrate from tropospheric heights. In the real world, GWs propagate obliquely with respect to the surface. However, because $k_{\mathrm{z}} \gg k_{\mathrm{h}}$ for most harmonics, $k_{\mathrm{h}}$ being the horizontal wavenumber, parameterizations (4) usually assume 
vertical-only propagation. Limitations of this approximation in the middle atmosphere have been recently discussed in the work by Kalisch et al. (2014), and higherorder effects have been found with a scheme employing ray tracing (Song et al. 2007). A special care should be taken with parameterizations extending to the thermosphere, where longer vertical wavelength harmonics (lower $k_{\mathrm{z}}$ ) tend to propagate to from below. In other words, all gravity waves accounted for by a parameterization must remain within their grid columns. Finally, (5) all column-based parameterizations employ a steadystate approximation. That is, transient processes of wave propagation assume an instantaneous response to changes in the forcing below. This approximation is suitable for modeling the general circulation; however, implications of time delay due to the finite group speed of wave packets should be carefully weighted for simulations of more rapid processes.

Parameterizations compute vertical profiles of a specified statistical quantity characterizing the GW field, such as horizontal velocity variance $\overline{u^{\prime 2}}$ (e.g., Medvedev and Klaassen 1995), or vertical flux of horizontal momentum $\overline{u^{\prime} w^{\prime}}$ (e.g., Yiğit et al. 2008). The former is convenient for comparison with observations of GW spectra. The latter is physically more lucid, because $\rho \overline{u^{\prime} w^{\prime}}$ is an invariant in a non-dissipative atmosphere. In GCMs, sources are specified by (1) prescribing the corresponding quantity at a certain level $z_{\mathrm{s}}$ in the lower atmosphere, or (2) calculating it interactively using large-scale fields resolved by the model as an input. The latter is sometimes called "parameterization of gravity wave sources". Because mechanisms of wave excitation in the lower atmosphere are numerous, each requires a separate approach. To date, physically based schemes suitable for GCMs have been developed for GWs excited by convection (Beres et al. 2004; Chun and Baik 2002), flow over topography (McFarlane 1987), and fronts (Charron and Manzini 2002). In most other modeling studies, spectra at a source level are prescribed based on observational constraints, or simply tuned to obtain desired simulated fields. A comprehensive comparison of GW fluxes in observations and modeling has recently been performed by Geller et al. (2013). Although many GCMs use time-independent source spectra, GW excitation can undergo large changes during transient events, such as SSWs. Therefore, the importance of such variations should be explored and their possible impacts on the general circulation have to be taken into account in whole atmosphere GCMs.

In the middle atmosphere, the main mechanism of GW obliteration is nonlinear breaking and/or saturation that occurs when amplitudes become large. Therefore, most GW parameterizations developed for middle atmosphere GCMs [starting from that of Lindzen (1981)] have in common that they terminate harmonics, whose amplitudes reach a certain instability threshold. Exceptions are the approaches of Hines (1997) ("Doppler spread") and Medvedev and Klaassen (1995) ("nonlinear diffusion"), which sought to describe the underlying physics. The former is based on the assumption that harmonics are Doppler shifted by varying wave-induced wind directly to very short scales where they are removed by molecular diffusion. When averaged over wave phases, this parameterization, however, yields the very same termination of harmonics employing ad hoc chosen criteria. The approach of Medvedev and Klaassen (1995) is based on the concept of "enhanced diffusion" (Weinstock 1976; Weinstock et al. 2007). It takes into account Doppler shift by large-scale harmonics in the spectrum, and erosion by short-scale ones. For parameterization purposes, Doppler shift can be neglected, the coefficient of eddyinduced diffusion is self-consistently calculated, and no "tuning parameters" are required (Medvedev and Klaassen 2000).

Gravity wave parameterizations suitable for thermosphere GCMs must account also for damping by molecular diffusion, thermal conduction, and ion friction. This is usually done by incorporating the respective dissipation terms into the complex dispersion relation in the form of imaginary parts of frequencies. The first parameterization of this kind has been proposed by Matsuno (1982), and the most recent derivation for molecular diffusion and thermal conduction has been performed by Vadas and Fritts (2005). This approach is based on the assumption that dissipation is relatively weak, where the degree of "weakness" depends on the characteristics of the harmonic and the background flow. This assumption constitutes another limitation on GW parameterizations. Molecular viscosity grows exponentially with height in the thermosphere, and eventually, the dissipation terms can significantly exceed all other balancing terms in the equations for waves. This means that GWs degenerate into other types ("viscous waves") and can no longer be considered within the parameterization framework.

We illustrate the principles outlined above and discuss some general details of implementation into a GCM using the extended nonlinear GW parameterization (Yiğit et al. 2008).

\section{The extended nonlinear spectral gravity wave parameterization}

The word "extended" denotes that the parameterization has been extended to account for wave propagation in the thermosphere in accordance with the requirements outlined above (Yiğit and Medvedev 2013). It solves the equation for the vertical structure of the horizontal momentum flux (per unit mass) $\overline{u^{\prime} w^{\prime}}$ associated with the harmonic $j$ from a given spectrum of waves: 


$$
\frac{\mathrm{d} \overline{u^{\prime} w_{j}^{\prime}}}{\mathrm{d} z}=-\left(\frac{\rho_{z}}{\rho}+\beta_{\mathrm{tot}}^{j}\right) \overline{u^{\prime} w^{\prime}},
$$

where $\beta_{\text {tot }}^{j}$ is the total vertical damping rate acting on the harmonic. If propagation is conservative $\left(\beta_{\text {tot }}^{j}=0\right)$, then the flux $\rho \overline{u^{\prime} w^{\prime}}$ is constant with height. The total damping rate for a given harmonic is the sum of the rates due to various dissipation processes affecting the propagation and acting simultaneously

$$
\beta_{\mathrm{tot}}^{j}=\beta_{\mathrm{non}}^{j}+\beta_{\mathrm{mol}}^{j}+\beta_{\mathrm{ion}}^{j}+\beta_{\mathrm{rad}}^{j}+\beta_{\mathrm{eddy}}^{j}+\cdots
$$

The main processes accounted for by the scheme include, correspondingly, nonlinear breaking/saturation $\left(\beta_{\text {non }}^{j}\right)$, molecular diffusion and thermal conduction $\left(\beta_{\mathrm{mol}}^{j}\right)$, ion friction $\left(\beta_{\text {ion }}^{j}\right)$, radiative damping $\left(\beta_{\text {rad }}^{j}\right)$, and eddy diffusion $\left(\beta_{\text {eddy }}^{j}\right)$ as suggested in the work by Yiğit et al. (2008). The term $\beta_{\text {non }}^{j}$ is parameterized after the work by Medvedev and Klaassen (2000) and comprises the effects of other harmonics on a given harmonic. Thus, the total wave field is not a simple collection of independent waves, but of interacting ones. The word "nonlinear" in the name of the parameterization signifies this property. Dissipation of a harmonic is strongly affected by changes in the background wind as the vertical damping is inversely proportional to the intrinsic phase speed of the harmonic, i.e., $\beta^{j} \propto\left(c_{j}-u\right)^{-n}$, where the exponent $n$ differs for various dissipation mechanisms (see, e.g., Yiğit and Medvedev 2013; Yiğit et al. 2008, 2009, 2012a). If the flux $\rho \overline{u^{\prime} w^{\prime}}$ j changes with height, the wave momentum is transferred to the mean flow by means of an acceleration or deceleration, which is often called "wave drag"

$$
a_{j}=-\frac{1}{\rho} \frac{\mathrm{d} \rho \overline{u^{\prime} w^{\prime}}}{\mathrm{d} z} .
$$

The total "drag" is determined by the gradient of the sum of fluxes for all $M$ harmonics in the spectrum, $\Sigma_{j}^{M} a_{j}$.

Equation (1) is solved for each grid column of a GCM. For that, values of $\overline{u^{\prime} w^{\prime}}{ }_{j}$ must be specified at a certain height $z_{s}$ in the lower atmosphere, which is considered as a source level. This initialization is done in all GW parameterizations, but the choice is extremely important for this scheme, because it contains no other tuning parameters, and the source spectrum is the only input. A representative spectrum can be seen in Yiğit et al. (Figure 1, 2009), where the fluxes are specified as functions of horizontal phase velocities, and based on the observations of Hertzog et al. (2008). The "asymmetric" spectrum takes into account an anisotropy with respect to the mean wind at the source level. The latter has been first suggested heuristically (Medvedev et al. 1998), and a possible explanation has been offered recently (Kalisch et al. 2014).
Gravity wave harmonics with larger vertical wavelengths are less affected by dissipation and, therefore, tend to propagate higher. Typical scale height $H$ also increases in the thermosphere (e.g., $H$ is around 50 at 250 $\mathrm{km}$ altitude). Because the parameterization is based on the WKB approximation ("Assumptions and limitations in gravity wave parameterizations" section), the vertical wavenumbers of accounted harmonics are limited by the relation $k_{\mathrm{z}} H \gg 1$. This relation translates into the limitation on the maximum phase velocities of GW harmonics considered in the parameterization to be $80-100 \mathrm{~m} \mathrm{~s}^{-1}$.

Using a GCM, the extended GW scheme has been extensively validated against the empirical horizontal wind model (HWM) (Yiğit et al. 2009) and the MSIS temperature distributions (Yiğit and Medvedev 2009). In a planetary atmospheres context, the extended scheme has successfully been used in a state-of-the art Martian GCM to investigate GW-induced dynamical and thermal coupling processes (Medvedev and Yiğit 2012; Medvedev et al. 2013, 2016; Yiğit et al. 2015).

\section{Effects of internal gravity waves on the general circulation of the upper atmosphere}

Given the statistical approach to parameterizing waves, in which all the information on wave phases is lost, and given the set of assumptions listed in "Assumptions and limitations in gravity wave parameterizations" section, no effects of individual wave packets can be simulated with GCMs. They can only be approached with GW-resolving models similar to that of Miyoshi et al. (2014). Historically, the need for accounting for GW effects emerged from an inability of GCMs to reproduce the observed zonal mean circulation in the middle atmosphere (Holton 1983). In particular, the inclusion of parameterized effects of subgrid-scale waves has helped to realistically simulate the semi-annual oscillation in the MLT (mesosphere and lower thermosphere) with a GCM (Medvedev and Klaassen 2001). Manson et al. (2002) demonstrated the same for solar tides. Recently, Schirber et al. (2014) have shown that, with the use of a convection-based GW scheme, a GCM has reproduced a quasi-biennial oscillation $(\mathrm{QBO})$ with realistic features.

Studying the effects of GWs of tropospheric origin in the thermosphere has a long history (see Yiğit and Medvedev 2015 for more detail); however, their dynamical importance at higher altitudes has not been fully recognized until recently. In all GCMs extending into the thermosphere, the effects of subgrid-scale GWs were either neglected, or assumed to decay exponentially above a certain height (e. g., turbopause $\sim 105 \mathrm{~km}$ ). Simulations of Yiğit et al. (2009) with the Coupled Middle Atmosphere and Thermosphere-2 (CMAT2, Yiğit 2009) GCM incorporating the extended nonlinear parameterization 
of Yiğit et al. (2008) revealed that the momentum deposition by lower atmospheric GWs in the F region is substantial and is comparable to that by ion drag. Figure 1 shows the latitude-altitude distribution of the simulated zonal mean zonal forcing by parameterized GWs. This forcing (known as "GW drag") is directed mainly against the mean zonal wind and plays an important role in the momentum balance of the upper thermosphere, similar to the scenario in the middle atmosphere. The magnitude of thermospheric GW drag, exceeding $\pm 200 \mathrm{~m} \mathrm{~s}^{-1}$ day $^{-1}$, is larger than its effects in the middle atmosphere.

Miyoshi et al. (2014)'s recent simulations with a whole atmosphere GW-resolving GCM have confirmed Yiğit et al. (2009)'s predictions of the appreciable dynamical effects of lower atmospheric GWs on the general circulation of the thermosphere above the turbopause. Figure 2 presents the divergence of momentum fluxes ( $a$ in Eq. 3) due to the resolved portion of GW spectra (with horizontal scales longer than $380 \mathrm{~km}$ ) calculated for solstice conditions (Miyoshi et al. 2014, Figure 3) as in the GCM modeling by Yiğit et al. (2009). Considering the various approximations and limitations of the extended parameterization, and especially, uncertainties with specifying GW sources, the two distributions in Figs. 1 and 2 appear to be in a good qualitative and quantitative agreement. There are also some differences between the two simulations. In particular, in the Southern

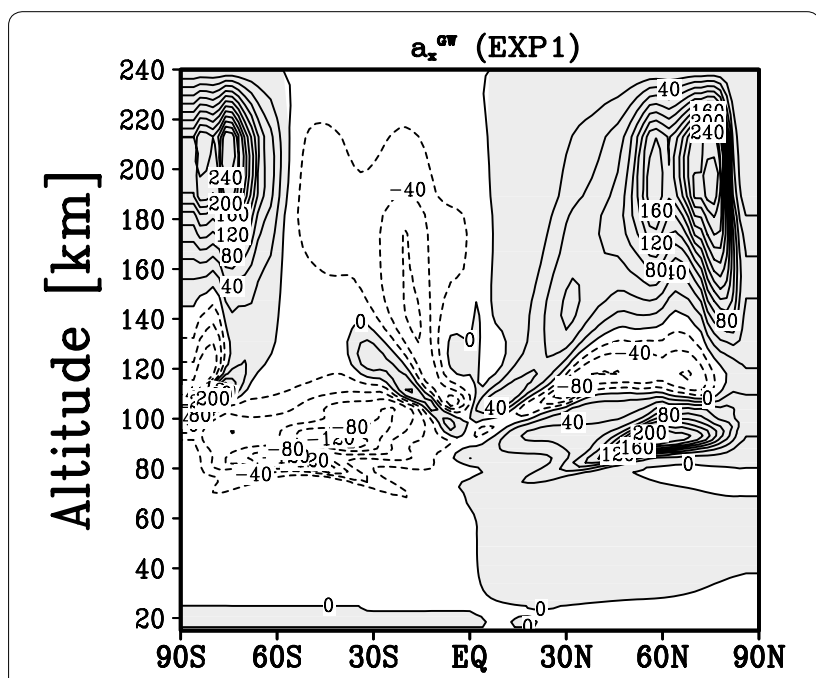

Fig. 1 Parameterized gravity wave drag. Altitude-latitude distribution of the parameterized zonal-mean zonal gravity wave drag (in $\mathrm{m} \mathrm{s}^{-1}$ day $^{-1}$ averaged over June/July solstice conditions based on the simulation with the CMAT2 GCM incorporating the whole atmosphere paramaterization of Yiğit et al. (2008). Solid and dashed lines denote eastward (positive) and westward (negative) zonal GW drag. After Yiğit and Medvedev (Figure 10, 2010)

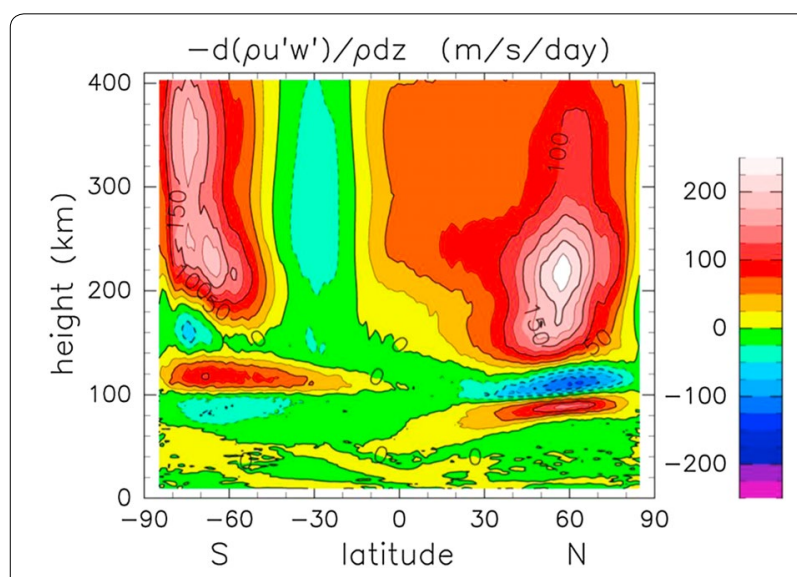

Fig. 2 Modeled zonal gravity wave drag. Same as in Fig. 1, but for the drag due to explicitly resolved gravity waves in simulations with the GAIA GCM. After Miyoshi et al. (Figure 3, 2014)

Hemisphere MLT, the high-resolution simulations show a region of eastward GW drag, which is only present at the Southern Hemisphere high- and low-latitudes in the parameterized simulation. Two possible sources of the discrepancies are the source spectrum and effects of the background winds on the propagation and the resulting dissipation. Overall, both simulation studies demonstrated that, due to propagation conditions in the middle atmosphere, most of the thermospheric GW activities concentrate at high latitudes, where solar tides modulate local time variations of GW drag. This and further analyses of the simulations with the high-resolution model provided evidences that thermospheric effects of GWs can be successfully parameterized in low-resolution GCMs.

Thermal effects of GWs are twofold: (a) heating due to conversion of the mechanical energy of dissipating harmonics into heat, and (b) heating and cooling associated with the downward sensible heat flux $\overline{w^{\prime} T^{\prime}}$ induced by these waves (Becker 2004; Medvedev and Klaassen 2003). Magnitudes of the former in the thermosphere are comparable with those due to the Joule heating, while the latter is comparable with the cooling rates due to molecular thermal conduction (Yiğit and Medvedev 2009), which suggests that the thermal effects of GWs cannot be neglected in the upper atmosphere. Yiğit and Medvedev (2010)'s GCM simulations with the extended scheme have demonstrated that the variations of thermospheric GW effects are appreciable. GWs propagate to higher altitudes during high solar activity, but produce weaker drag than during periods of low solar activity. Their observations have later been qualitatively verified by the satellite observations of Park et al. (2014). 


\section{Sudden stratospheric warmings Characteristics}

Sudden stratospheric warmings first discovered observationally by Scherhag (1952) are transient events during which the eastward zonal mean zonal winds weaken, or even reverse the direction at $60^{\circ} \mathrm{N}$ (geographic) at $\sim 30$ $\mathrm{km}(10 \mathrm{hPa})$, followed by the significant warming of the winter North Pole $\left(90^{\circ} \mathrm{N}\right)$ (Andrews et al. 1987; Labitzke 1981). Since the 1950s, as the interest in studying SSWs has grown, the classification of SSWs has evolved (see Butler et al. 2015, for a comprehensive discussion). Essentially, there are two commonly accepted types of warmings: a minor and a major warming. The warming is major if the equator-to-pole temperature gradient reverses poleward of $60^{\circ}$ latitude in addition to the reversal of the zonal mean zonal winds at $60^{\circ} \mathrm{N}$ at $10 \mathrm{hPa}$ (Labitzke 1981). If the westerly mean zonal wind weakens but does not reverse the direction, i.e., the stratospheric vortex does not break down, during a temperature increase at the pole, then the warming is defined as a minor event.

An illustration of the major SSW features is seen in Fig. 3 for a representative major warming that took place in the winter of 2008-2009, as adopted from the work by Goncharenko et al. (2010, Figure 1). These stratospheric conditions are based on data from the National Center for Environmental Prediction (NCEP). Within about 5 days, the zonal mean temperature at $10 \mathrm{hPa}$ increases
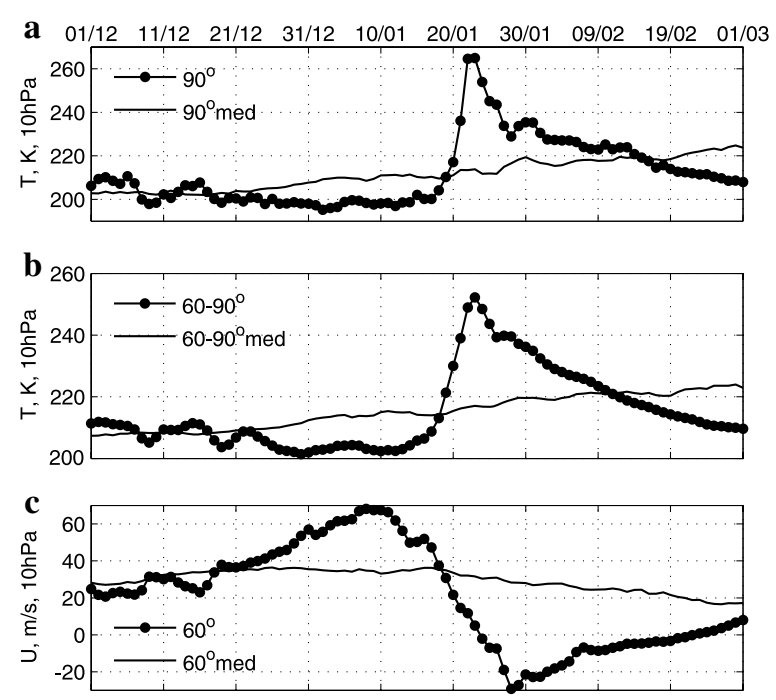

Fig. 3 The 2008-2009 sudden stratospheric warming. Variation of the stratospheric conditions at $10 \mathrm{hPa}$ during the sudden stratospheric warming that took place in the winter of 2008-2009 according to data from the National Center for Environmental Predictions (NCEP). a Stratospheric temperature at $90^{\circ} \mathrm{N} ; \mathbf{b}$ mean temperature at $60^{\circ} \mathrm{N}-90^{\circ} \mathrm{N} ; \mathbf{c}$ mean zonal wind at $60^{\circ} \mathrm{N}$. Thin lines represent 30 -year means of stratospheric parameters. Adopted from Goncharenko et al. (2010, Figure 1) by more than $60 \mathrm{~K}$ (from 200 to more than $260 \mathrm{~K}$ ) at the North Pole, that is, more than $30 \%$ increase (top panel). The average temperature at high latitudes $\left(60^{\circ} \mathrm{N}-90^{\circ} \mathrm{N}\right)$ increases significantly as well. The eastward (positive) zonal mean zonal wind starts decelerating already before the onset of the warming at the Pole and reverses its direction, reaching a minimum over a period of about 10 days (bottom panel). The thin solid curves in each panel show the 30-year means of the associated parameters. Goncharenko et al. (2010) have also demonstrated in their analysis that the 2008-2009 warming was related to a weakening of the planetary wave- 1 and an enhancement of the wave- 2 .

A comprehensive review of the earlier theoretical explanations of SSWs can be found in the works by Schoeberl (1978) and Holton (1980). Earlier studies have indicated that planetary-scale waves have to be properly taken into account during warming periods. According to the seminal work of Charney and Drazin (1961), planetary-scale disturbances can propagate from the troposphere into the stratosphere in the presence of prevailing westerlies, and the transport of eddy heat and momentum by vertically propagating waves is expected to modify the stratospheric zonal flow. Initial idealized simulations of wave propagation have suggested that planetary waves with wave numbers 1 and 2 can reach the stratosphere (Matsuno 1970). Matsuno (1971) modeled that Rossby wavemean flow interactions decelerate the polar night jet, leading to weakening and even breakdown of the polar vortex, and ultimately to a sudden warming of the polar region. Later, the numerical works by Holton (1976) and Palmer (1981) have qualitatively provided supporting evidence for Matsuno (1971)'s model.

\section{Mechanism of the sudden warming}

In the winter (solstice) period, the Northern Hemisphere stratosphere is dominated by westerly jets whose strength increases with altitude. Quasi-stationary planetary waves can propagate vertically upward, provided that the mean zonal flow satisfies the conditions for vertically propagating wave modes. For these waves, the zonal wind has to fulfill the following condition (Holton and Hakim 2012, Equation (12.16)):

$$
0<\bar{u}<u_{c},
$$

where the Rossby critical velocity $u_{\mathrm{c}}$ is defined in terms of the characteristics of the background atmosphere and wave by

$$
u_{\mathrm{c}} \equiv \beta k_{\mathrm{h}}^{2}+\frac{f_{0}^{2}}{4 N^{2} H^{2}},
$$

where $k_{\mathrm{h}}^{2}=k^{2}+l^{2}$ is the horizontal wavenumber that depends on the zonal $\left(k=2 \pi / \lambda_{\mathrm{x}}\right)$ and the meridional 
( $\left.l=2 \pi / \lambda_{\mathrm{y}}\right)$ wavenumbers; $f=f_{0}-\beta y$ is the beta-plane approximation for the Coriolis parameter, and $\beta \equiv \frac{\partial f}{\partial y}$ is the meridional gradient of the Coriolis parameter. The condition (4) suggests that planetary waves can propagate vertically only in the presence of westerly winds that are weaker than a certain critical value $u_{c}$, which depends on the horizontal scale of the wave. Dynamical conditions are, therefore, favorable for the vertical propagation of planetary waves in the winter Northern Hemisphere with prevalent mean westerly winds. This condition is important for understanding the propagation of GWs, which are also affected by the mean wind distributions. Namely, before the warming, the stratospheric zonal mean winds are eastward. They filter out a significant portion of the eastward directed GWs, favoring the upward propagation of harmonics with phase velocities directed westward. During the warmings, the decelerating westerlies increase the chances of GWs with eastward horizontal phase speeds to propagate to higher altitudes (Yiğit and Medvedev 2012).

In the winter stratosphere, waves are rapidly attenuated, thus decelerating the mean zonal flow. For the occurrence of SSWs, a large-scale wave transience, in particular, rapid temporal changes of planetary wave activity are also important. They maintain the convergence of the westward momentum flux, leading to strong polar night jet deceleration and poleward meridional flow enhancement (Andrews et al. 1987). Additionally, radiative forcing sustains a cold winter North Pole with negative equator-to-pole mean temperature gradient, that is, $\frac{\partial T}{\partial y}<0$. The rapid deceleration of the stratospheric mean flow implies a decreasing (positive) vertical gradient of the zonal flow between the troposphere and stratosphere. From the thermal wind relation $\frac{\partial u}{\partial z} \sim-\frac{\partial T}{\partial y}$, this decrease implies a rise of temperature at the winter pole, meaning that the equator-to-pole mean temperature gradient becomes less negative. During a major warming, this gradient even reverses due to the reversal of the vertical gradient of zonal mean wind. The strong polar night jet deceleration leads to a departure from the thermal wind balance, and the poleward meridional flow, which is caused by the Coriolis force associated with the westward forcing, is induced to recover this balance. This enhancement of the Brewer-Dobson circulation ultimately results in an adiabatic warming at Northern Hemisphere high latitudes.

\section{Observed changes in the upper atmosphere during sudden stratospheric warmings}

Given the rapid and strong local changes in the circulation and thermal structure of the stratosphere during SSWs, the natural questions that bear in mind are (1) how high the effects of the warming propagate in altitude, and
(2) to what extent the changes in the upper atmosphere can be associated with the sudden warmings. Planetary waves cannot propagate directly to much higher altitudes, but the stratosphere and mesosphere are closely connected via circulation and by GWs and tides. As sudden warmings and the associated dynamical changes in the stratosphere occur over relatively long time scales (e.g., $\sim 10$ days) compared to the periods of internal waves, lower atmospheric wave disturbances have sufficient time to propagate to higher altitudes, provided that propagation conditions are favorable. Therefore, one ought to expect a certain degree of coupling between the stratosphere and higher altitudes, probably beyond the middle atmosphere.

How can one associate observed upper atmospheric changes with SSWs? Essentially, a ground-to-upper atmosphere observation with a single instrument is beyond the capabilities of the current technology. For the purposes of observational analysis, SSW events/periods ought to be identified. For this, an appropriate description of stratospheric dynamics is needed in the first place. This representation could be, for example, obtained from numerical forecast models that assimilate in situ and remote-sensing data, such as the European Centre for Medium-Range Weather Forecast (ECMWF) analyses, and produce the required global fields of atmospheric parameters. Then, observational data can be investigated together with the numerical model output (e.g., Pancheva et al. 2008).

The deceleration of the stratospheric eastward zonal flow during sudden warmings leads, ultimately, to an upward circulation in the mesosphere that results in mesospheric cooling (Liu and Roble 2002). Such direct link between these two regions has motivated a number of scientists to investigate the details of stratosphere-mesosphere changes during warmings. Based on temperature and geopotential height data obtained from the sounding the atmosphere using broadband emission radiometry (SABER) instrument of the thermosphere ionosphere mesosphere energetics and dynamics (TIMED) satellite and the VHF radar horizontal winds, Pancheva et al. (2008) have investigated planetary wave-induced coupling in the stratosphere-mesosphere during the major warming of 2003/2004 winter Northern Hemisphere.

Yuan et al. (2012) studied the response of the middlelatitude mesopause region to the 2009 major SSW, using a sodium Doppler wind-temperature lidar. They have discovered anomalous behavior of the mean temperature and zonal winds around the mesopause during the warming and concluded that it was due to a direct impact of the major warming on the middle-latitude mesopause. The 2009 SSW has been one of the strongest warming events that has been recorded. The features around the 
mesopause during SSWs can be largely characterized in terms of an "elevated stratopause", which forms around 75-80 km after the SSW occurrence and then descends (Maney et al. 2009). The role of GWs and planetary-scale waves in the time evolution of the elevated stratopause have been investigated by a number of authors (e.g., Chandran et al. 2011; Limpasuvan et al. 2012; Siskind et al. 2010).

Vertical coupling between the stratosphere and the lower thermosphere has been studied in the lowand middle-latitude Northern Hemisphere winter of 2003/2004 based on the temperature data from SABER/ TIMED (Pancheva et al. 2009). According to Goncharenko and Zhang (2008)'s analysis of the Millstone Hill incoherent scatter radar (ISR) ion temperatures data, warming in the lower thermosphere and cooling above $150 \mathrm{~km}$ were revealed during a minor SSW. Using data from the Jicamarca ISR, Chau et al. (2009) have detected significant semidiurnal tidal variations in the vertical $\mathbf{E} \times \mathbf{B}$ ion drifts in the equatorial ionosphere during the winter 2007-2008 minor warming. Using temperature measurements from the Michelson interferometer for passive atmospheric sounding (MIPAS) on board European Space Agency's (ESA) Envisat satellite measurements, Funke et al. (2010) have demonstrated observational evidence for the dynamical coupling between the lower and upper atmosphere during the 2009 major SSW. Based on TEC (total electron content) data retrieved from a worldwide network of GPS observations, Goncharenko et al. (2010) have found a significant local time modulation of the equatorial ionization anomaly (EIA) induced by SSWs. Using the European Incoherent Scatter (EISCAT) UHF radar, Kurihara et al. (2010) have detected short-term variations in the upper atmosphere during the 2009 major warming. In their analysis of Fabry-Perot and incoherent scatter radar data, Conde and Nicolls (2010) have identified that the period of reduced neutral temperatures at $240 \mathrm{~km}$, which corresponded closely to the main phase of the warming.

More recently, analyzing the Constellation Observing System for Meteorology Ionosphere and Climate (COSMIC) data, Pancheva and Mukhtarov (2011) have found a systematic negative response of ionospheric plasma parameters $\left(f_{0} F_{2}, h_{\mathrm{m}} F_{2}\right.$, and $\left.n_{\mathrm{e}}\right)$ during the warmings of 2007-2008 and 2008-2009. An illustration of their results for the mean zonal mean electron density (in $\mathrm{MHz}$ ) at 300 $\mathrm{km}$ is shown in Fig. 4, where the 2007-2008 and 20082009 warming events are shown in the left and right panels, respectively. The response to the warming is negative and mainly occurs in the low- and middle-latitude region. Liu et al. (2011) used neutral mass density observations from the Challenging Minisatellite Payload (CHAMP) and Gravity Recovery and Climate Experiment (GRACE) satellites to study the thermospheric variations during the 2009 major warming. They have found a substantial decrease of the mass density and concluded that it was potentially associated with a strong thermospheric cooling of about $50 \mathrm{~K}$. Goncharenko et al. (2013) have investigated the day-to-day variability in the middle-latitude ionosphere during the 2010 major warming using the Millstone Hill ISR. They have discovered that semidiurnal and terdiurnal tidal variations were enhanced during the SSW. Jonah et al. (2014) have used a suit of observational data from GPS, magnetosphere, and meteor radar to investigate the response of the magnetosphere and ionosphere to the 2013 major SSW. Analyzing long-term data of the global average thermospheric total mass density derived from satellite orbital drag, Yamazaki et al. (2015) showed density reduction of 3-7 \% at 250-575 $\mathrm{km}$ during SSW period that can be associated with lower atmospheric forcing. Recently, using data from GPS and ionosonde stations, Fagundes et al. (2015) investigated the response of the low- and middle-latitude ionosphere in the Southern Hemisphere to the 2009 major SSW and found that during the warming, TEC was depressed following the SSW temperature peak.

Overall, these studies (1) suggest that a variety of instruments has been used to study upper atmospheric changes during SSWs; (2) convincingly demonstrated that SSW events affect the thermosphere-ionosphere system beyond the turbopause; and (3) suggest that the associated observed changes in the upper atmosphere vary from one warming event to another. Some studies indicate that large-scale internal wave processes may be involved in vertical coupling during SSWs. One of the less appreciated topics in SSW studies is the role of small-scale GWs. We next discuss the upper atmosphere changes during SSWs in the context of lower atmospheric small-scale GWs that can propagate to the thermosphere (Yiğit et al. 2009, 2012a).

\section{Upper atmospheric changes during sudden stratospheric warmings}

Observing dynamical changes, e.g., with satellites and radars, cannot provide sufficiently detailed information on characteristics and physical mechanisms of vertical coupling. Observations may, and in fact, do raise new questions, which can be investigated by models. A powerful tool is GCMs that solve the coupled governing equations of atmospheric and ionospheric physics in time and three-dimensional space. GCMs generate a full set of field parameters that can be diagnosed in detail to investigate the physical mechanisms that shape the state and evolution of the atmosphere. Therefore, global models can provide an unprecedented insight in vertical coupling processes between the different atmospheric 

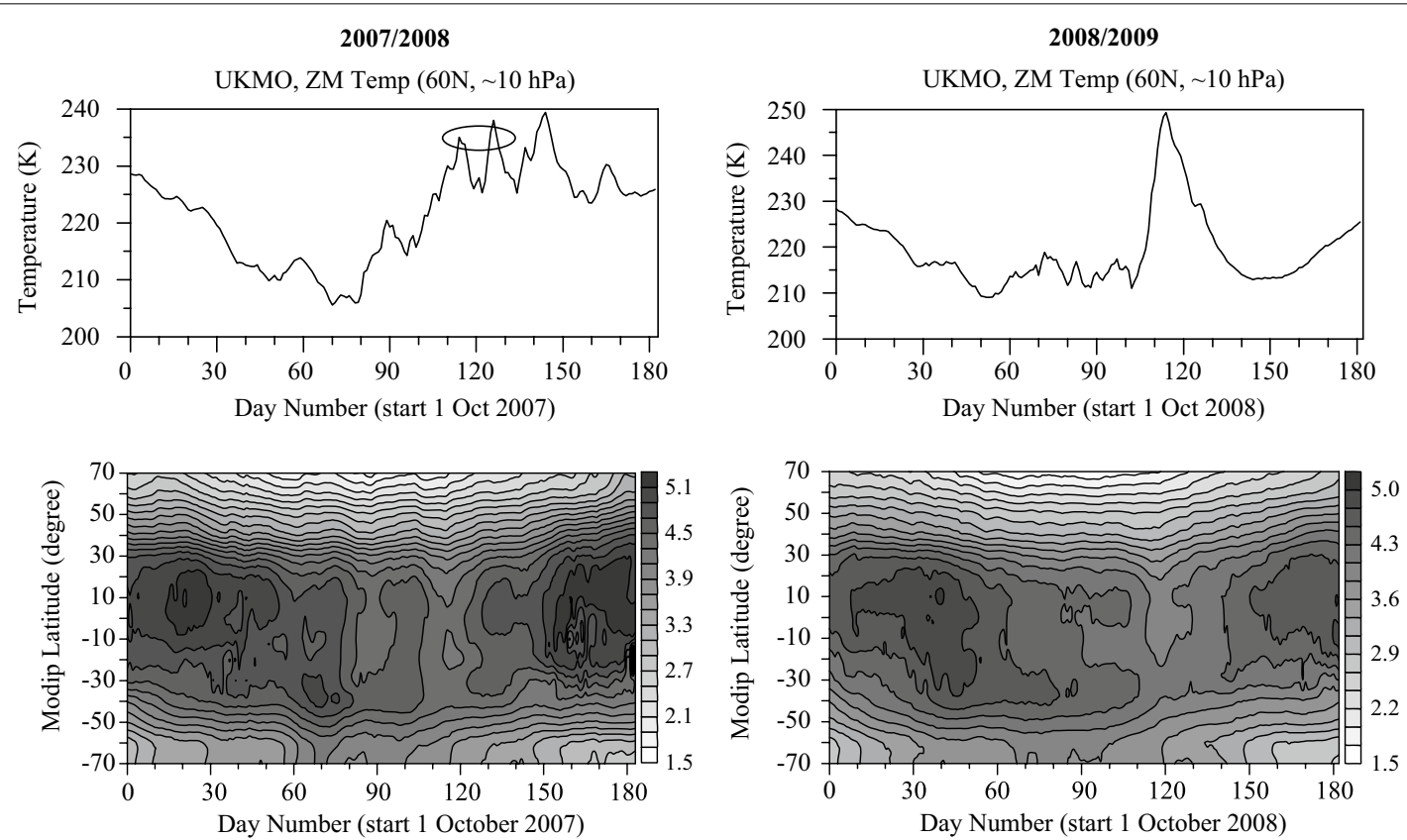

Fig. 4 SSW event and ionospheric variations. The upper panels show the 2007/2008 (left) and 2008/2009 (right) SSWs according to the UK Met Office (UKMO) model. The zonal mean temperatures at $60^{\circ} \mathrm{N}$ are plotted for the two SSWs at $10 \mathrm{hPa}$ as a function of day number. The ellipse shows the temperature peaks during the warming. In the lower panels, the associated variations of the mean zonal mean electron density (in $\mathrm{MHz}$ ) retrieved from COSMIC at $300 \mathrm{~km}$ during the two warmings are seen. Adopted from Pancheva and Mukhtarov $(2011$, Figures 1, 2)

regions. One should nevertheless be aware of the limitations of GCMs, such as resolution, boundary conditions, and parameterizations.

As discussed in "Effects of internal gravity waves on the general circulation of the upper atmosphere" section, GWs have a profound effect on the dynamical (Miyoshi et al. 2014; Vadas et al. 2014; Yiğit et al. 2009, 2012a), thermal (Hickey et al. 2011; Yiğit and Medvedev 2009) and compositional (Walterscheid and Hickey 2012) structure of the upper atmosphere. The state of the background middle atmosphere plays a crucial role in modulating the propagation of GWs into the thermosphere. Given that SSWs modify the middle atmospheric circulation significantly, how can they influence the upper atmosphere in the context of GW propagation and dissipation in the thermosphere? Resolving this science question requires a use of comprehensive GCMs with appropriate representation of small-scale GWs. The GCM study of Yiğit and Medvedev (2012) using the extended nonlinear GW parameterization of Yiğit et al. (2008) has demonstrated GW propagation and appreciable dynamical effects in the upper thermosphere during a minor warming. The universal time (UT) variations of the GW-induced zonal mean root-mean-square (RMS) wind fluctuations (in $\mathrm{m} \mathrm{s}^{-1}$ ) and zonal mean GW drag (in $\mathrm{m} \mathrm{s}^{-1}$ day $^{-1}$ ) are shown in Fig. 5a and b. GW-induced RMS wind fluctuations are given by $\sigma=\left(M^{-1} \sum_{j}^{M} \overline{u_{j}^{\prime 2}}\right)^{1 / 2}$, where $M$ is the number of harmonics in the spectrum and variance $\overline{u_{j}^{\prime 2}}$ is related to the wave amplitude as $\sqrt{\overline{u_{j}^{\prime 2}}} \equiv\left|u_{j}^{\prime}\right|$. The GW RMS wind fluctuations are a proxi for the subgrid-scale GW activity as the fluctuations induced by all waves in a GW spectrum are taken into account and do not represent the resolved wind fluctuations. In the course of the warming, GW activity increases by a factor of 3 exceeding $6 \mathrm{~m} \mathrm{~s}^{-1}$ in response to weakening of the polar night jet. In addition to persistently large values in the lower thermosphere, modulation of the GW activity is seen higher in the thermosphere. Following the increase of GW activity, (eastward) GW drag increases in the thermosphere during the warming as well.

The effects of GWs in the upper atmosphere during SSWS are not confined to only those in a zonal mean sense. Recently, Yiğit et al. (2014) have investigated the details of GW temporal variations in the thermosphere during a minor warming simulated with a GCM. They modeled that GW drag and its variability are dramatically enhanced in the thermosphere during the warming and thus lead to a $\sim \pm 50 \%$ modulation of small-scale and short-term variability in the resolved thermospheric winds, where the small-scale variability has been evaluated by subtracting the contributions of the large-scale tides. Recently, Miyoshi et al. (2015) have demonstrated with a GW-resolving GCM that the SSW has major dynamical and thermal impact on the upper atmosphere, substantially influencing the global circulation. 


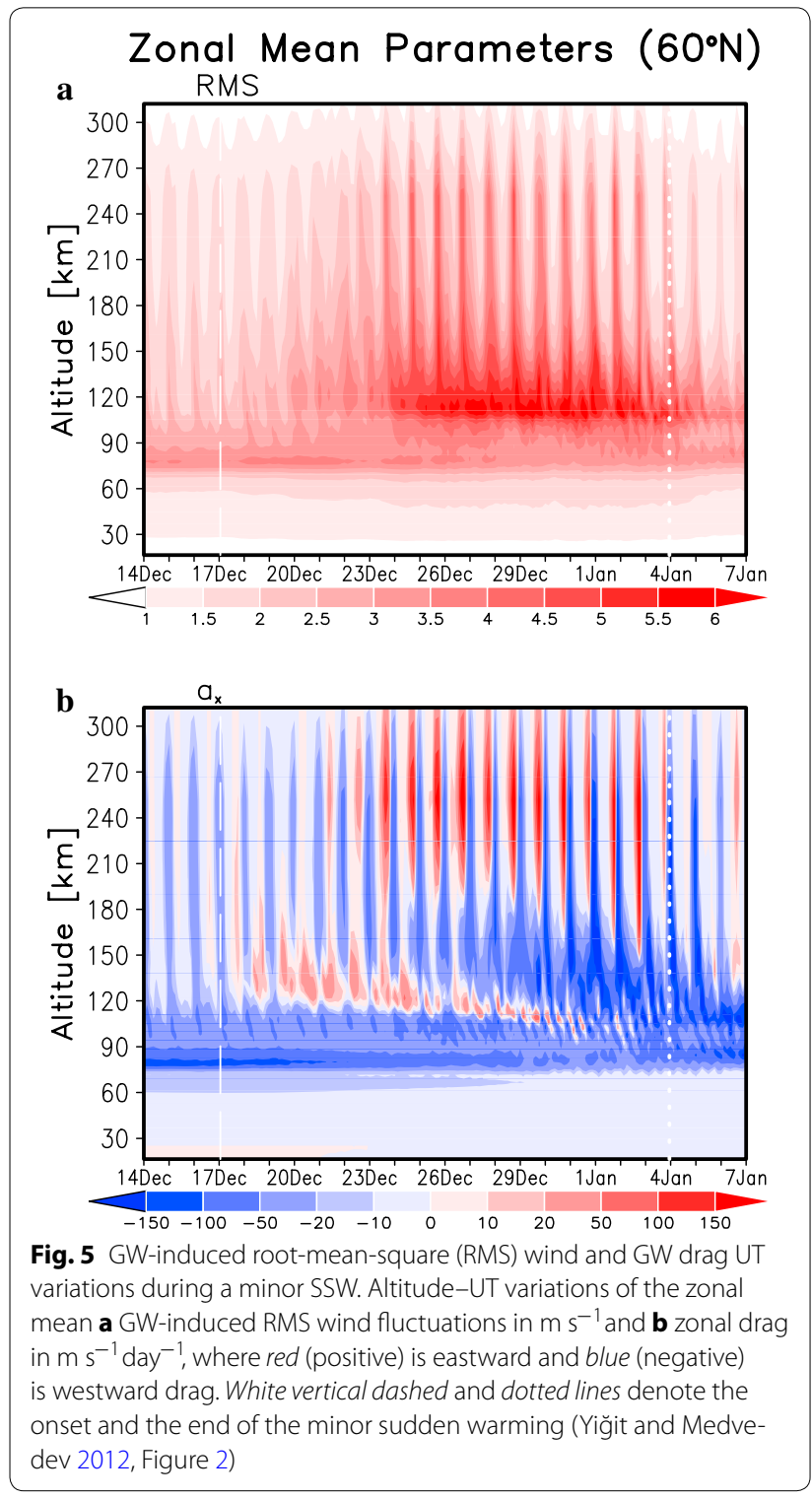

Changes in the mean zonal wind produce a feedback on GWs by modifying filtering, dissipation, and propagation conditions.

The upper atmosphere above the turbopause has a great amount of variability owing to the simultaneous influences of meteorological and space weather processes (Anderson et al. 2011; Matsuo et al. 2003; Yiğit and Ridley 2011b; Yiğit et al. 2012b). Often, separating the components and sources of variability in observations is a challenging task. Thus, following their observations of an SSW, Kurihara et al. (2010) have concluded that understanding the link between SSWs and thermal and dynamical changes in the upper atmosphere-ionosphere requires investigations of $\mathrm{GW}$-mean flow interactions processes. GCM studies can greatly supplement these efforts.
Predictions with GCMs indicate that small-scale GWs can substantially contribute to the variability of the upper atmosphere. Also, recent modeling studies with a whole atmosphere GCM have shown an enhancement of the semidiurnal variation in the ionospheric $\mathbf{E} \times \mathbf{B}$ drifts during the 2009 major warming (Jin et al. 2012). This increase has been interpreted as a consequence of the semidiurnal tidal amplification in the lower atmosphere. Further investigations that incorporate a fully two-way coupled thermosphere-ionosphere under the influence of lower atmospheric waves are required to assess the significance of the lower atmosphere in the context of upper atmosphere variability. In characterizing the upper atmosphere processes, the variability is always defined with respect to some appropriate mean. Therefore, the quantity of variability is not uniquely defined, and care should be taken when comparing one study to another. In a broader context, the presence of any kind of variability restricts scientists' ability to predict the future state of the atmosphere, and it is crucial to determine the sources of variability and quantify the magnitude thereof.

\section{Conclusions}

This paper has briefly reviewed the current state of knowledge and most recent developments with understanding the role of GWs in vertical coupling during SSWs. The observed upper atmosphere changes during SSWs have been presented. An emphasis was placed on the processes above the mesopause, and on how they can be studied with GCMs.

The geosciences community increasingly recognizes that the effects of lower atmospheric gravity waves extend beyond the middle atmosphere into the atmosphere-ionosphere system and are of global nature. Similarly, sudden stratospheric warmings were used to be looked upon as stratospheric phenomena, but now compelling observational evidences of their signatures in the thermosphere-ionosphere are being routinely provided.

With the rapid progress in the field of atmospheric coupling, further key science questions on the role of GWs in coupling atmospheric layers arise:

- What are the spectra of gravity waves in the lower and upper atmosphere? How do they change during the different phases of SSWs?

- How well do GW parameterizations describe wave spectra and reproduce their effects during SSWs?

- What is the relative role of GW- and electrodynamical coupling between atmospheric layers in the variability of the atmosphere-ionosphere system during SSWs? 
- What are the effects of GWs on the circulation and thermal budget of the upper atmosphere during major sudden stratospheric warmings?

- Do GWs in the upper atmosphere affect the development of sudden stratospheric warmings, or they are a mere reflection of processes in the lower atmosphere?

- Do GWs have a role in latitudinal coupling in the thermosphere during SSW events?

This is certainly an incomplete list of scientific questions, answering which requires concerted observational, theoretical, and modeling efforts from scientists of both lower and upper atmosphere communities.

\section{Authors' contributions}

Both authors have participated in writing all sections. Both authors read and approved the final manuscript.

\section{Author details}

${ }^{1}$ Department of Physics and Astronomy, George Mason University, 4400 University Drive, Fairfax, VA 22030, USA. ${ }^{2}$ Max Planck Institute for Solar System Research, Göttingen, Justus-von-Liebig-Weg 3, 37077 Göttingen, Germany.

${ }^{3}$ Institute of Astrophysics, Georg-August University, Göttingen, Germany.

\section{Acknowledgements}

The work was partially supported by German Science Foundation (DFG) Grant ME2752/3-1. EY was partially supported by NASA Grant NNX13AO36G and NSF Grant AGS 1452137.

\section{Competing interests}

The authors declare that they have no competing interests.

Received: 22 February 2016 Accepted: 28 July 2016

Published online: 24 August 2016

\section{References}

Anderson C, Davies T, Conde M, Dyson P, Kosch MJ (2011) Spatial sampling of the thermospheric vertical wind field at auroral latitudes. J Geophys Res 116:A07305

Andrews DG, Holton JR, Leovy CB (1987) Middle atmosphere dynamics, international geophysics series. Academic Press, Dublin

Becker E (2004) Direct heating rates associated with gravity wave saturation. J Atmos Sol Terr Phys 66:683-696

Becker E (2011) Dynamical control of the middle atmosphere. Space Sci Rev 168:283-314

Beres JH, Alexander MJ, Holton JR (2004) A method of specifying the gravity wave spectrum above convection based on latent heating properties and background wind. J Atmos Sci 61(3):324-337

Butler AH, Seidel DJ, Hardiman SC, Butchart N, Birner T, Match A (2015) Defining sudden stratospheric warmings. Bull Am Meteorol Soc 96(11):19131928 2014JE004715

Chandran A, Collins RL, Garcia RR, Marsh DR (2011) A case study of an elevated stratopause generated in the whole atmosphere community climate model. Geophys Res Lett 38(8):L08804. doi:10.1029/2010GL046566

Charney JG, Drazin PG (1961) Propagation of planetary-scale disturbances from the lower into the upper atmosphere. J Geophys Res 66(1):83-109

Charron M, Manzini E (2002) Gravity waves from fronts: parameterization and middle atmosphere response in a general circulation model. J Atmos Sci 59(5):923-941

Chau JL, Fejer BG, Goncharenko LP (2009) Quiet variability of equatorial e $\times$ b drifts during a sudden stratospheric warming event. Geophys Res Lett 36:L05101
Chun HY, Baik JJ (2002) An updated parameterization of convectively forced gravity wave drag for use in large-scale models. J Geophys Res 59(5):1006-1017

Conde MG, Nicolls MJ (2010) Thermospheric temperatures above Poker Flat, Alaska, during the stratospheric warming event of January and February (2009). J Geophys Res Atmos 115(D3):d00N05. doi:10.1029/201 OJD014280

Fagundes PR, Goncharenko LP, de Abreu AJ, Venkatesh K, Pezzopane M, de Jesus R, Gende M, Coster AJ, Pillat VG (2015) lonospheric response to the 2009 sudden stratospheric warming over the equatorial, low, and middle latitudes in the South American sector. J Geophys Res Space Phys 120(9):7889-7902. doi:10.1002/2014JA020649

Fritts DC, Alexander MJ (2003) Gravity wave dynamics and effects in the middle atmosphere. Rev Geophys 41:1003

Fritts DC, Lund TC (2011) Gravity wave influences in the thermosphere and ionosphere: observations and recent modeling. In: Aeronomy of the earth's atmosphere and ionosphere, IAGA special sopron book series. Springer, Berlin, pp 109-130. doi:10.1007/978-94-007-0326-1_8

Funke B, López-Puertas M, Bermejo-Pantaleón D, Garcia-Comas M, Stiller GP, von Clarmann T, Kiefer M, Linden A (2010) Evidence for dynamical coupling from the lower atmosphere to the thermosphere during a major stratospheric warming. Geophys Res Lett 37(13). doi:10.1029/2010GL043619

Garcia RR, Solomon S (1985) The effect of breaking gravity waves on the dynamics and chemical composition of the mesosphere and lower thermosphere. J Geophys Res 90:3850-3868

Geller M, Alexander MJ, Love PT, Bacmeister J, Ern M, Hertzog A, Manzini E, Preusse P, Sato K, Scaife AA, Zhou T (2013) A Comparison between gravity wave momentum fluxes in observations and climate models. J Clim 26:6383-6405

Goncharenko L, Zhang SR (2008) lonospheric signatures of sudden stratospheric warming: Ion temperature at middle latitude. Geophys Res Lett 35:L21103

Goncharenko LP, Coster AJ, Chau JL, Valladares CE (2010) Impact of sudden stratospheric warmings on equatorial ionization anomaly. J Geophys Res 115:A00G07

Goncharenko LP, Hsu VW, Brum CGM, Zhang SR, Fentzke JT (2013) Wave signatures in the midlatitude ionosphere during a sudden stratospheric warming of january 2010. J Geophys Res Space Phys 118:472-487

Heale CJ, Snively JB, Hickey MP (2014) Thermospheric dissipation of upward propagating gravity wave packets. J Geophys Res Space Phys 119(5):3857-3872. doi:10.1002/2013JA019387

Hertzog A, Boccara G, Vincent RA, Vial F, Cocquerez P (2008) Estimation of gravity wave momentum flux and phase speeds from quasi-lagrangian stratospheric balloon flights. Part ii: results from the Vorcore campaign in Antarctica. J Atmos Sci 65:3056-3070

Hickey MP, Cole KD (1988) A numerical model for gravity wave dissipation in the thermosphere. J Atmos Terr Phys 50:689-697

Hickey MP, Walterscheid RL, Schubert G (2010) Wave mean flow interactions in the thermosphere induced by a major tsunami. J Geophys Res Space Phys 115(A9). doi:10.1029/2009JA014927

Hickey MP, Walterscheid RL, Schubert G (2011) Gravity wave heating and cooling of the thermosphere: sensible heat flux and viscous flux of kinetic energy. J Geophys Res 116:A12326

Hines CO (1960) Internal gravity waves at ionospheric heights. Can J Phys 38:1441-1481

Hines CO (1997) Doppler spread parameterization of gravity wave momentum deposition in the middle: 1. basic formulation. J Atmos Sol Terr Phys 59:371-386

Holton JR (1976) A semi-spectral numerical model for wave-mean flow interactions in the stratosphere: application to sudden stratospheric warmings. J Atmos Sci 33:1639-1649

Holton JR (1980) The dynamics of stratospheric warmings. Ann Rev Earth Planet Sci 8:169-190

Holton JR (1983) The influence of gravity wave breaking on the general circulation of the middle atmosphere. J Atmos Sci 40:2497-2507

Holton JR, Hakim GJ (2012) An introduction to dynamic meteorology. Academic Press, Dublin

Jin H, Miyoshi Y, Pancheva D, Mukhtarov P, Fujiwara H, Shinagawa H (2012) Response of migrating tides to the stratospheric sudden warming in 2009 and their effects on the ionosphere studied by a whole atmosphere-ionosphere model GAIA with COSMIC and TIMED/SABER observations. J Geophys Res 117:A10323 
Jonah OF, de Paula ER, Kherani EA, Dutra SLG, Paes RR (2014) Atmospheric and ionospheric response to sudden stratospheric warming of January 2013. J Geophys Res Space Phys 119(6):4973-4980. doi:10.1002/2013JA019491

Kalisch S, Preusse P, Ern M, Eckermann SD, Riese M (2014) Differences in gravity wave drag between realistic oblique and assumed vertical propagation. $J$ Geophys Res Atmos 119:10,081-10,099

Klostermeyer J (1972) Influence of viscosity, thermal conduction, and ion drag on the propagation of atmospheric gravity waves in the thermosphere. Z Geophysik 38:881-890

Kurihara J, Ogawa Y, Oyama S, Nozawa S, Tsutsumi M, Hall CM, Tomikawa Y, Fujii $R$ (2010) Links between a stratospheric sudden warming and thermal structures and dynamics in the high-latitude mesosphere, lower thermosphere, and ionosphere. Geophys Res Lett 37:L13806

Labitzke K (1981) Stratospheric-mesospheric midwinter disturbances: a summary of observed characteristics. J Geophys Res 86(C10):9665-9678

Laštovička J (2006) Forcing of the ionosphere by waves from below. J Atmos Sol Terr Phys 68:479-497

Limpasuvan V, Richter JH, Orsolini YJ, Stordal F, Kvissel OK (2012) The roles of planetary and gravity waves during a major stratospheric sudden warming as characterized in WACCM. J Atmos Sol Terr Phys 78-79:84-98

Lindzen RS (1981) Turbulence and stress owing to gravity waves and tidal breakdown. J Geophys Res 86:9707-9714

Liu H, Doornbos E, Yamamoto M, Ram ST (2011) Strong thermospheric cooling during the 2009 major stratosphere warming. Geophys Res Lett 38:L12102

Liu HL, Roble RG (2002) A study of a self-generated stratospheric sudden warming and its mesospheric-lower thermospheric impacts using the coupled TIME-GCM/CCM3. J Geophys Res 107(15-1):15-18

Manney GL, Schwartz MJ, Krüger K, Santee ML, Pawson S, Lee JN, Daffer WH, Fuller RA, Livesey NJ (2009). Aura microwave limb sounder observations of dynamics and transport during the record-breaking 2009 Arctic stratospheric major warming. Geophys Res Lett 36(12). doi:10.1029/200 9GLO38586

Manson AH, Meek CE, Koshyk J, Franke S, Fritts DC, Riggin D, Hall CM, Hocking WK, MacDougall J, Igarashi K, Vincent RA (2002) Gravity wave activity and dynamical effects in the middle atmosphere (60-90 km): observations from an MF/MLT radar network, and results from the Canadian Middle Atmosphere Model (CMAM). J Atmos Sol Terr Phys 64:65-90

Matsuno T (1970) Vertical propagation of stationary planetary waves in the winter northern hemisphere. J Atmos Sci 27:871-883

Matsuno T (1971) A dynamical model of the stratospheric sudden warming. J Atmos Sci 28:1479-1494

Matsuno T (1982) A quasi one-dimensional model of the middle atmosphere circulation interacting with internal gravity waves. J Meteor Soc Japan 60:215-226

Matsuo T, Richmond AD, Hensel K (2003) High-latitude ionospheric electric field variability and electric potential derived from DE-2 plasma drift measurements: dependence on IMF and dipole tilt. J Geophys Res 108(A1):1005

McFarlane NA (1987) The effect of orographically excited gravity wave drag on the general circulation of the lower stratosphere and troposphere. J Atmos Sci 44:1775-1800

Medvedev AS, Klaassen GP (1995) Vertical evolution of gravity wave spectra and the parameterization of associated wave drag. J Geophys Res 100:25,841-25,853

Medvedev AS, Klaassen GP (2000) Parameterization of gravity wave momentum deposition based on nonlinear wave interactions: basic formulation and sensitivity tests. J Atmos Sol Terr Phys 62:1015-1033

Medvedev AS, Klaassen GP (2001) Realistic semiannual oscillation simulated in a middle atmosphere general circulation model. Geophys Res Lett 28:733-736

Medvedev AS, Klaassen GP (2003) Thermal effects of saturating gravity waves in the atmosphere. J Geophys Res 108(D2):4040

Medvedev AS, Yiğit E (2012) Thermal effects of internal gravity waves in the Martian upper atmosphere. Geophys Res Lett 39:L05201

Medvedev AS, Klaassen GP, Beagley SR (1998) On the role of an anisotropic gravity wave spectrum in maintaining the circulation of the middle atmosphere. Geophys Res Lett 25:509-512

Medvedev AS, Yiğit E, Kuroda T, Hartogh P (2013) General circulation modeling of the martian upper atmosphere during global dust storms. J Geophys Res 118:1-13
Medvedev AS, Nakagawa H, Mockel C, Yiğgit E, Kuroda T, Hartogh P, Terada K, Terada N, Seki K, Schneider NM, Jain SK, Evans JS, Deighan JI, McClintock WE, Lo D, Jakosky BM (2016) Comparison of the martian thermospheric density and temperature from iuvs/maven data and general circulation modeling. Geophys Res Lett 43(7):3095-3104. doi:10.1002/2016GL068388

Miyoshi Y, Fujiwara H (2008) Gravity waves in the thermosphere simulated by a general circulation model. J Geophys Res 113:D011101

Miyoshi Y, Fujiwara H, Jin H, Shinagawa H (2014) A global view of gravity waves in the thermosphere simulated by a general circulation model. J Geophys Res Space Phys 119:5807-5820

Miyoshi Y, Miyoshi Y, Fujiwara H, Jin H, Shinagawa H (2015) Impacts of sudden stratospheric warming on general circulation of the thermosphere. J Geophys Res Space Phys 120(12):10,897-10,912. doi:10.1002/201 5JA021894

Palmer TN (1981) Diagnostic study of a wavenumber-2 stratospheric sudden warming in a transformed Eulerian-mean formalism. J Atmos Sci 38:844-855

Pancheva D, Mukhtarov P (2011) Stratospheric warmings: the atmosphereionosphere coupling paradigm. J Atmos Sol Terr Phys 73:1697-1702

Pancheva D, Mukhtarov P, Mitchell NJ, Merzlyakov E, Smith AK, Andonov B, Singer W, Hocking W, Meek C, Manson A, Murayama Y (2008) Planetary waves in coupling the stratosphere and mesosphere during the major stratospheric warming in 2003/2004. J Geophys Res Atmos 113(D12). doi:10.1029/2007JD009011

Pancheva D, Mukhtarov P, Andonov B, Mitchell NJ, Forbes JM (2009) Planetary waves observed by TIMED/SABER in coupling the stratosphere-mesosphere-lower thermosphere during the winter of 2003/2004: part 1comparison with the UKMO temperature results. J Atmos Sol Terr Phys 71:61-74

Park J, Lühr H, Lee C, Kim YH, Jee G, Kim J-H (2014) A climatology of mediumscale gravity wave activity in the midlatitude/low-latitude daytime upper thermosphere as observed by CHAMP. J Geophys Res Space Phys 119. doi:10.1002/2013JA019705

Prölss GW (2011) Density perturbations in the upper atmosphere caused by the dissipation of solar wind energy. Surv Geophys 32

Scherhag R (1952) Die explosionsartige Stratosphärenerwärmung des Spätwinters 1951-1952. Ber Deut Wetterdienstes 6:51-63

Schirber S, Manzini E, Alexander MJ (2014) A convection-based gravity wave parameterization in a general circulation model: implementation and improvements on the QBO. J Adv Model Earth Syst 6:264-279

Schoeberl MR (1978) Stratospheric warmings: observation and theory. Rev Geophys 16(4):521-538

Siskind DE, Eckermann SD, McCormack JP, Coy L, Hoppel KW, Baker NL (2010) Case studies of the mesospheric response to recent minor, major, and extended stratospheric warmings. J Geophys Res 115:D00N03

Song IS, Chun HY, Garcia RR, Boville BA (2007) Momentum flux spectrum of convectively forced internal gravity waves and its application to gravity wave drag parameterization. Part II: impacts in a GCM (WACCM). J Atmos Sci 34:2286-2308

Vadas S, Liu H (2009) Generation of large-scale gravity waves and neutral winds in the thermosphere from the dissipation of convectively generated gravity waves. J Geophys Res 114:A10310

Vadas SL, Fritts DC (2005) Thermospheric responses to gravity waves: influences of increasing viscosity and thermal diffusivity. J Geophys Res 110:D15103

Vadas SL, Liu HL, Lieberman RS (2014) Numerical modeling of the global changes to the thermosphere and ionosphere from the dissipation of gravity waves from deep convection. J Geophys Res Space Phys 119(9):7762-7793. doi:10.1002/2014JA020280

Walterscheid RL, Hickey MP (2012) Gravity wave propagation in a diffusively separated gas: effects on the total gas. J Geophys Res 117:A05303

Weinstock J (1976) Nonlinear theory of acoustic-gravity waves 1. Saturation and enhanced diffusion. J Geophys Res 81:633-652

Weinstock J, Klaassen GP, Medvedev AS (2007) Reply to comments on the gravity wave theory of $J$. Weinstock concerning dissipation induced by nonlinear effects. J Atmos Sci 64:1027-1041

Yamazaki Y, Kosch MJ, Emmert JT (2015) Evidence for stratospheric sudden warming effects on the upper thermosphere derived from satellite orbital decay data during 1967-2013. Geophys Res Lett 42:6180-6188

Yiğit E (2009) Modelling atmospheric vertical coupling: role of gravity wave dissipation in the upper atmosphere. PhD Thesis, University College London Doctoral Thesis 
Yiğit E, Medvedev AS (2009) Heating and cooling of the thermosphere by internal gravity waves. Geophys Res Lett 36:L14807

Yiğit E, Medvedev AS (2010) Internal gravity waves in the thermosphere during low and high solar activity: simulation study. J Geophys Res 115:A00G02

Yiğit E, Medvedev AS (2012) Gravity waves in the thermosphere during a sudden stratospheric warming. Geophys Res Lett 39:L21101

Yiğit E, Medvedev AS (2013) Extending the parameterization of gravity waves into the thermosphere and modeling their effects. In: Lübken FJ (ed) Climate and weather of the sun-earth system (CAWSES), Springer Atmospheric Sciences, Berlin :467-480. doi:10.1007/978-94-007-4348-9_25

Yiğit E, Medvedev AS (2015) Internal wave coupling processes in earth's atmosphere. Adv Space Res 55(5):983-1003. http://www.sciencedirect. com/science/article

Yiğit E, Ridley AJ (2011a) Effects of high-latitude thermosphere heating at various scale sizes simulated by a nonhydrostatic global thermosphereionosphere model. J Atmos Sol Terr Phys 73:592-600

Yiğit E, Ridley AJ (2011b) Role of variability in determining the vertical wind speeds and structure. J Geophys Res 116:A12305

Yiğit E, Aylward AD, Medvedev AS (2008) Parameterization of the effects of vertically propagating gravity waves for thermosphere general circulation models: sensitivity study. J Geophys Res 113:D19106
Yiğit E, Medvedev AS, Aylward AD, Hartogh P, Harris MJ (2009) Modeling the effects of gravity wave momentum deposition on the general circulation above the turbopause. J Geophys Res 114:D07101

Yiğit E, Medvedev AS, Aylward AD, Ridley AJ, Harris MJ, Moldwin MB, Hartogh $P$ (2012a) Dynamical effects of internal gravity waves in the equinoctial thermosphere. J Atmos Sol Terr Phys 90-91:104-116

Yiğit E, Ridley AJ, Moldwin MB (2012b) Importance of capturing heliospheric variability for studies of thermospheric vertical winds. J Geophys Res 117:A07306

Yiğit E, Medvedev AS, England SL, Immel TJ (2014) Simulated variability of the high-latitude thermosphere induced by small-scale gravity waves during a sudden stratospheric warming. J Geophys Res Space Phys 119

Yiğit E, Medvedev AS, Hartogh P (2015) Gravity waves and high-altitude $\mathrm{CO}_{2}$ ice cloud formation in the Martian atmosphere. Geophys Res Lett 42. doi:10.1002/2015GL064275

Yuan T, Thurairajah B, She CY, Chandran A, Collins RL, Krueger DA (2012) Wind and temperature response of midlatitude mesopause region to the 2009 sudden stratospheric warming. J Geophys Res 117:D09114

\section{Submit your manuscript to a SpringerOpen ${ }^{\circ}$ journal and benefit from:}

- Convenient online submission

- Rigorous peer review

Immediate publication on acceptance

- Open access: articles freely available online

- High visibility within the field

- Retaining the copyright to your article 